\title{
Estudo da influência da substituição do cimento Portland por resíduo de cerâmica vermelha na fabricação de placas de fibrocimento
}

\author{
Study of the influence of the replacement of \\ Portland cement by red ceramic residue in \\ the manufacture of fiber cement boards
}

${ }^{1}$ Universidade Tecnológica Federal do Paraná, Via do Conhecimento, km 03, Bairro Fraron, CEP 85503-390, Pato Branco, PR, Brasil.

e-mail: claudiabaldin@utfpr.edu.br, ilofilho@yahoo.com.br, vbaldin@utfpr.edu.br

\section{RESUMO}

Atualmente, os resíduos da indústria de cerâmica vermelha apresentam-se como uma alternativa em potencial para uso em matrizes cimentícias como adição mineral ou pozolana de baixa reatividade. Este estudo, teve como objetivo avaliar a influência da substituição parcial do cimento CP V ARI por resíduo da indústria de cerâmica vermelha em placas de fibrocimento. O cimento foi substituído em volume nas percentagens de 0 , 15,25 e $50 \%$. Essas combinações foram reforçadas com fibras de celulose e polipropileno (PP). A investigação foi realizada analisando ensaios de fluorescência de raios X, difração de raios - X, microscopia eletrônica de varredura e análise termogravimétrica. Além disso, ensaios de resistência mecânica à flexão das placas foram realizadas em amostras produzidas com base em um processo de sucção e prensagem. Todos os ensaios foram realizados com amostras aos 28 dias de hidratação. Os resultados da caracterização microestutural apresentaram uma redução do hidróxido de cálcio conforme aumenta o teor de RCV devido ao consumo deste composto em consequência da reação pozolânica, também foram observados picos de C-S-H em todas as misturas. Considerando- se os resultados das propriedades mecânicas à flexão, todos os percentuais de substituição apresentaram resultados satisfatórios de acordo com a norma NBR 15498 em relação à resistência à flexão para uso em fachadas externas.

Palavras-chave: Resíduos de cerâmica vermelha. Placas de fibrocimento. Análise microestrutural. Resistência mecânica à flexão.

\begin{abstract}
Currently, the waste of the red ceramic industry presented as a potential alternative for use in cementitious matrices such as mineral or pozzolan addition of low reactivity. This study had as objective evaluate the influence of partial replacement of CP V ARI cement by the red ceramic industrywaste on fiber cement plates. The cement was replaced to volume in the percentages of $0,15,25$ and $50 \%$. These combinations were reinforced with cellulose and polypropylene (PP) fibers. The investigation was perform tests including X-ray diffraction, scanning electron microscopy and thermogravimetric Analysis. Moreover, mechanical flexural strength tests of the boards were performed on samples produced based on a suction and pressing process. All test were performed with samples at 28 days of hydration. The results of the microstructural characterization showed a reduction of calcium hydroxide as the RCV content increases, due to the consumption of this compound as result of the pozzolanic reaction, $\mathrm{C}-\mathrm{S}-\mathrm{H}$ peaks were also observed in all mixtures. Considering the results of the flexural mechanical properties, all percentages of substitution presented satisfactory results in
\end{abstract}


accordance with the NBR 15498 standard referring flexural strength for use on external facades.

Keywords: Red ceramics waste. Fiber cement boards. Microstructural analysis. flexural mechanical strength.

\section{INTRODUÇÃO}

A produção de cerâmica vermelha no Brasil gera aproximadamente 6,5 milhões de toneladas de resíduos que podem ser valorizados através do seu uso em matrizes cimentícias. Com um controle de qualidade e estudos para verificação da composição química e mistura adequada, esses resíduos podem ser incorporados na produção de componentes construtivos em substituição parcial ao cimento ou como adições minerais [1].

Diversos estudos vêm sendo conduzidos a fim de investigar o potencial do uso do resíduo de cerâmica vermelha (RCV) moído como adição ou substituição do cimento Portland em argamassas e concretos. No entanto pouco se sabe desse comportamento em artefatos cimentícios ou em placas de fibrocimento[2-6]. Segundo ANJOS et. al. (2002), [7], a substituição do cimento Portland por RCV em compósitos representa uma economia no custo do produto final e também podem contribuir com o aumento da durabilidade e das propriedades físicas.

Propriedades físicas das placas de fibrocimento podem ser melhoradas com a inclusão do resíduo de RCV como material fino. Este resíduo geralmente atua em concretos e argamassas de forma que complementam as misturas, contribuindo para o aumento da resistência mecânica pelo efeito físico (fíler), onde a distribuição do tamanho das partículas acarretam melhor empacotamento da mistura, ou ainda, pela presença de fases ativas presentes no RCV que definem o grau de atividade pozolânica [2]. Sendo a pozolana um material inorgânico, natural ou artificial, constituída de materiais silicosos ou sílico-aluminosos que, moídos finamente, passante em peneira de $75 \mu \mathrm{m}$ e em presença de água, reagem como hidróxido de cálcio presente em matrizes cimentícias formando compostos mais estáveis, geralmente C-S-H (Silicato de Cálcio Hidratado), o que contribui para o preenchimento dos poros na fase sólida desses materiais [8].

Dentre as principais razões já mencionadas para a prática da substituição parcial do cimento por RCV, pode-se destacar ainda a redução no consumo de energia elétrica, térmica e emissões de $\mathrm{CO}_{2}$ associados a produção do cimento, redução de danos ambientais relacionado com a destinação final do resíduo e ainda a valorização do mesmo [9]. Neste contexto, o objetivo do presente estudo é avaliar qual o teor ótimo de substituição do cimento Portland por RCV em relação a resistência mecânica à flexão três pontos e a influência dessa substituição na microestrutura das placas de fibrocimento.

\section{MATERIAIS E MÉTODOS}

\subsection{Materiais}

Para confecção das placas de fibrocimento foram utilizados o cimento Portland sem adição mineral (CP V ARI), o fíler calcário e o RCV, além das fibras curtas de origem vegetal (celulose) e fibras de polipropileno (PP), CQ Fiber, com comprimento nominal máximo de 12,0 $\mathrm{mm}$ para reforço das matrizes cimentícias.

O RCV foi coletado na indústria de cerâmica vermelha, oriundo da produção de blocos e telhas, localizada na região Sudoeste do estado do Paraná, considerado o Polo da indústria de cerâmica vermelha do estado. A preparação do RCV consistiu na secagem em estufa por aproximadamente 24 horas em temperatura controlada de $105^{\circ} \mathrm{C}$, em seguida foram triturados em moinho de bolas com posterior peneiramento na peneira com abertura de malha $150 \mu \mathrm{m}(\# 100)$.

Para identificação e composição química do RCV foi empregada a técnica de Fluorescência de Raios X. O equipamento empregado foi o "Panalytical, Axios Max: Tubo Ródio 4 kv.

Para o cimento CP V ARI os dados de composição química foram fornecidas pelo fabricante. Além disso, realizou-se o ensaio de atividade pozolânica normatizado pela NBR 5752:2014 [12] afim de verificar qual o índice de atividade pozolânica do RCV.

As características físicas de densidade e superfície específica dos materiais foram determinadas por meio dos ensaios realizados em laboratório, com base na NBR 16372:2015 [10] para o ensaios de superfície específica (método Blaine) e a NBR 16605:2017[11] para determinação da massa específica aparente.

As propriedades mecânicas foram determinadas por meio do ensaio de flexão à três pontos na máquina universal de ensaio AROTEC, célula de carga de $100 \mathrm{kN}$, com velocidade de deslocamento de $5,0 \mathrm{~mm} / \mathrm{min}$., conforme NBR 15498 (ABNT, 2016).

O DRX foi realizado no equipamento da marca Rigaku, modelo Mini Flex. A visualização da microes- 
trutura na superfície das placas, foi por meio de um microscópio eletrônico de varredura, EVO, MA15, com filamento de tungstênio e câmara para amostras de até $250 \mathrm{~mm}$ de diâmetro e massa de $500 \mathrm{~g}$ com movimento total do estágio (XYZ e inclinação). As análises termogravimétricas foram realizadas em $20^{\circ} \mathrm{C} / \mathrm{min}$ no equipamento STA6000 PerkinElmer, cadinho de platina com 6mg de amostra, atmosfera de $\mathrm{N}^{2}$ (pureza 5.0) em uma faixa de temperatura entre 20 à $900^{\circ} \mathrm{C}$.

A visualização da microestrutura na superfície das placas foi por meio de um detector de imagem de elétrons retroespalhamento, operado a $15 \mathrm{Kv}$, utilizando-se do equipamento Vega3, Tescan e Oxford INCAxact, resolution at $5.9 \mathrm{Ke}$. Todas as amostras foram preparadas com uma camada superfícial de recobrimento em ouro.

\subsection{Métodos}

A definição nos teores de 15, 25 e 50\% de substituição do CP V ARI pelo RCV foi dada em volume, sendo apresentado na Tabela 1 a proporção em massa dos materiais empregados nas misturas.

Tabela 1: Proporção das misturas: Fração em massa dos materiais secos.

\begin{tabular}{c|c|c|c|c|c}
\hline ID DA MISTURA & $\begin{array}{c}\text { CP V ARI } \\
\text { (\%) }\end{array}$ & RCV (\%) & $\begin{array}{c}\text { FÍLER } \\
\text { CALCÁRIO (\%) }\end{array}$ & $\begin{array}{c}\text { FIBRAS DE } \\
\text { CELULOSE (\%) }\end{array}$ & $\begin{array}{c}\text { FIBRAS DE } \\
\text { PP (\%) }\end{array}$ \\
\hline PV0 & 68,5 & 0 & 27 & 1,5 & 3 \\
\hline PV15 & 57,54 & 9,30 & 27 & 1,5 & 3 \\
\hline PV25 & 51,38 & 14,50 & 27 & 1,5 & 3 \\
\hline PV50 & 34,25 & 29 & 27 & 1,5 & 3 \\
\hline
\end{tabular}

O processo de produção das placas foi pelo método Hatschek, adaptado para escala laboratorial, similar ao empregado por BETIOLI et al. (2011), CALDAS E SILVA (2002) e URREA-CEFERINO (2017) [13 15]. Esse método consiste na dispersão inicial das fibras com a água, em seguida a mistura dos demais materiais secos em uma argamassadeira adaptada com hélice tipo centrífuga. Finalizado o processo de mistura, o material é lançado em uma fôrma de aço galvanizada nas dimensões de 200 mm x 200 mm x 10 mm, acoplada por uma base inferior perfurada e uma bomba de vácuo para sucção do excesso de água da suspensão. Logo após retirar as placas das formas o grupo de três peças de uma mesma série são colocadas na prensa, intercaladas com chapas metálicas e telas de drenagem, sendo submetidas à uma carga de 3,2 MPa durante 5 minutos [16].

Após a prensagem, foi determinada a massa de cada placa para verificação aproximada da relação água/cimento $(\mathrm{A} / \mathrm{C})$ da mistura, sendo observado um valor médio de $0,28 \mathrm{~g} / \mathrm{g}$. Todas as amostras foram mantidas em cura submersa por 7 dias e em seguida colocados em câmara úmida (temperatura de $23^{\circ} \mathrm{C}$ e umidade relativa à $50 \% \mathrm{RH}$ ) até os 28 dias, afim de simular o que ocorre em algumas indústrias de placas de fibrocimento.

Para o ensaio de resistência à flexão três pontos, foram retiradas quatro amostras para cada concentração nas dimensões de $160 \mathrm{~mm}$ x $40 \mathrm{~mm}$ x $10 \mathrm{~mm}$, sendo realizado conforme NBR 15498 (ABNT, 2016). Com quatro amostras para cada composição e idade de hidratação, sendo utilizado a Equação 1 para o cálculo do módulo de ruptura (MOR). Todos os resultados foram analisados estatisticamente de acordo com o teste paramétrico de análise de variância (ANOVA - Teste de Tukey).

$M O R=3 P l / 2 b d^{2}$

\footnotetext{
Onde:

$M O R=$ Módulo de ruptura (Mpa);

$P=$ Carga máxima aplicada $(\mathrm{N})$;

$l=$ vão inferior entre cutelos $(\mathrm{mm})$;

$b=$ largura do corpo-de-prova (mm);

$d=$ espessura do corpo-de-prova $(\mathrm{mm})$
}

Para a investigação da microestrutura, foram recolhidas amostras fraturadas de todas as placas submetidas a resistência mecânica à flexão. Essas amostras foram submetidas às técnicas de Difração de Raios X (DRX), Microscopia eletrônica de Varredura (MEV) e Análise termogravimétrica (TG/DTG) na idade de 28 
dias.

A interrupção da hidratação consistiu em fraturar as amostras e colocá-las submersas em acetona P.A, onde ficaram em repouso por duas horas. Posteriormente, o excesso de acetona foi retirado, com o auxílio de um funil e um papel filtro com gramatura de $80 \mathrm{~g}$, em seguida as amostras colocadas num filtro de Buchner acoplado à bomba a vácuo para suç̧ão da acetona restante. Após secas, para completar o processo, as amostras foram deixadas em temperatura controlada (aproximadamente $40^{\circ} \mathrm{C}$ ) por 24 horas e então trituradas em granulometria inferior a $75 \mu \mathrm{m}$ para as análises de DRX e TG/DTG. Para o MEV as amostras foram preparadas previamente com impregnação em resina epóxi, polidas manualmente em uma máquina lixadeira politriz usando papel abrasivo de carboneto de silício com granulometria sequencial de 400, 600 e 1200por aproximadamente 10 minutos, usando álcool isopropílico (99,8\% de pureza) como lubrificante.

\section{RESULTADOS}

\subsection{Caracterização dos materiais}

Todos os resultados relacionados a composição química do cimento CP V ARI e o RCV estão apresentados na Tabela 2, onde pode-se observar que o resíduo apresenta maiores teores de $\mathrm{SiO}_{2}, \mathrm{Al}_{2} \mathrm{O}_{3}, \mathrm{Fe}_{2} \mathrm{O}_{3}$ e $\mathrm{MgO}$ e menor teor de $\mathrm{CaO}$. Em relação ao ensaio de atividade pozolânica do RCV constatou-se um índice de pozolanicidade $94 \%$, sendo superior aos $75 \%$ definidos pela norma, sendo considerado reativo.

Tabela 2: Composição química do RCV e do cimento CP V ARI

\begin{tabular}{|c|c|c|}
\hline COMPONENTE & RCV (TEOR \%) & CP V ARI(TEOR \%) \\
\hline $\mathrm{SiO}_{2}$ & 70,87 & 18,91 \\
\hline $\mathrm{Al}_{2} \mathrm{O}_{3}$ & 18,11 & 4,35 \\
\hline $\mathrm{Fe}_{2} \mathrm{O}_{3}$ & 4,57 & 2,69 \\
\hline $\mathrm{CaO}$ & 0,06 & 60,59 \\
\hline $\mathrm{MgO}$ & 1,07 & 4,74 \\
\hline $\mathrm{K}_{2} \mathrm{O}$ & 1,85 & - \\
\hline $\mathrm{Na}_{2} \mathrm{O}$ & 0,07 & - \\
\hline $\mathrm{TiO}_{2}$ & 0,71 & - \\
\hline $\mathrm{MnO}$ & 0,05 & - \\
\hline $\mathrm{P}_{2} \mathrm{O}_{5}$ & 0,05 & - \\
\hline $\mathrm{SO}_{3}$ & - & 2,86 \\
\hline *P.F. & 3,13 & 2,89 \\
\hline outros & - & 1,34 \\
\hline Soma & 100,53 & 98,37 \\
\hline
\end{tabular}

As características físicas de densidade e superfície específica dos materiais estão descritas na Tabela 3. Observa-se que a massa específica do RCV é menor em relação ao cimento Portland e ao fíler calcário utilizado na pesquisa, contribuindo para a menor densidade do material em conjunto com as fibras.

Tabela 3: Massa específica de todos os componentes da placas e superfície específica dos aglomerantes obtida pelo método de permeabilidade ao ar (permeabilímetro de Blaine).

\begin{tabular}{l|l|l}
\hline MATERIAL & MASSA ESPECÍFICA & SUPERFÍCIE ESPECÍFICA \\
\hline CP V ARI & $3,09 \mathrm{~g} / \mathrm{cm}^{3}$ & $4451 \mathrm{~cm}^{2} / \mathrm{g}$ \\
\hline Fíler Calcário & $2,70 \mathrm{~g} / \mathrm{cm}^{3}$ & $4576 \mathrm{~cm}^{2} / \mathrm{g}$ \\
\hline RCV & $2,61 \mathrm{~g} / \mathrm{cm}^{3}$ & $12902 \mathrm{~cm}^{2} / \mathrm{g}$ \\
\hline Fibra PP & $0,82 \mathrm{~g} / \mathrm{cm}^{3}$ & - \\
\hline
\end{tabular}




\begin{tabular}{l|l|l}
\hline Fibra de celulose & $0,50 \mathrm{~g} / \mathrm{cm}^{3}$ & - \\
\hline
\end{tabular}

\subsection{Resistência mecânica à flexão}

A Figura 1 apresenta os resultados do módulo de ruptura (MOR) das placas de fibrocimento, formuladas com substituição parcial de cimento CP V - ARI por RCV em $0 \%, 15 \%, 25 \%$ e $50 \%$.

Para todas as misturas foi possível observar um aumento na resistência de 7 para 28 dias de hidratação o que já era esperado, decorrente do processo de hidratação do cimento. No entanto, o teste de significância dos resultados de resistência à flexão das placas de fibrocimento aos 28 dias de hidratação apontou que não há diferença significativa entre as misturas, considerando um nível de confiança de 95\% (Tabela 4).

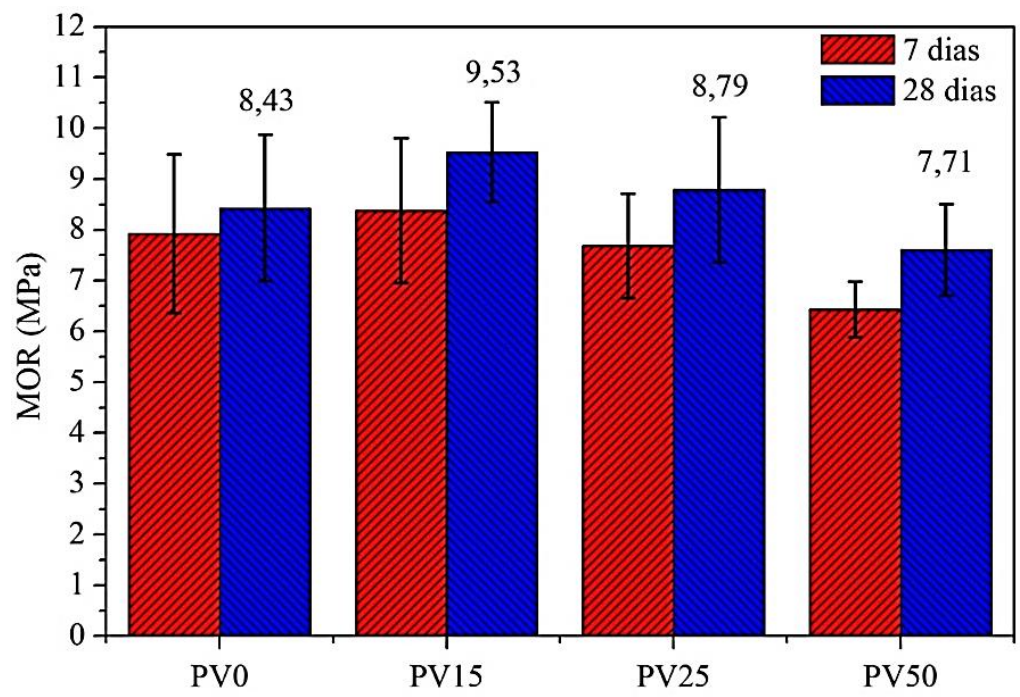

Figura 1: Módulo de ruptura à flexão das placas de fibrocimento aos 7 (coluna vermelha) e 28 dias (coluna azul).

Tabela 4: Teste de significância para as placas de fibrocimento, aos 28 dias de hidratação.

\begin{tabular}{|c|c|c|c|c|c|}
\hline \multicolumn{6}{|c|}{ TESTE DE SIGNIFICÂNCIA PARA PLACAS CP V-ARI :0\%, 15\%, 25\% E 50\% DE RCV } \\
\hline & df (Grau de liberdade) & SS (Soma dos Quadrados) & MS (Quadrado médio) & $\mathrm{F}$ & $\mathrm{P}$ \\
\hline ID & 3 & 7,732 & 2,577 & 1,747 & 0,211 \\
\hline Resíduos & 12 & 17,702 & 1,475 & - & - \\
\hline
\end{tabular}

\subsection{Difração de Raios X}

A Figura 2 representa os difratogramas das placas de fibrocimento produzidas com cimento CP V - ARI, e substituições de $0 \%, 15 \%, 25 \%$ e 50\% de RCV, aos 28 dias. Observa-se uma redução nos picos de Hidróxido de Cálcio $(\mathrm{CH})$, conforme ficha cristalográfica (grupo espacial P3 (-) m1) com identificação dos principais picos em $18,05^{\circ}, 34,20^{\circ}$ e $47,31^{\circ}$ (2Ө), aumento nos picos cristalinos de quartzo (Q) em $21,20^{\circ}, 23,26^{\circ}$ e $27,20^{\circ}(2 \Theta)$, (grupo espacial P3 (2) 21) e também a presença da hematita (H) em picos de $36,04^{\circ}$ e $41,19^{\circ}$ (2Ө), (grupo espacial (0)) conforme ocorre o aumento no teor de RCV. Indicando dessa forma, que o $\mathrm{CH}$ pode estar sendo consumido na formação de C-S-H, como também pode ser verificado pela análise termogravimétrica. Os padrões de DRX das placas segue a identificação dos picos encontrados também por ARAUJO (2017) [2] em argamassas produzidas com RCV. 


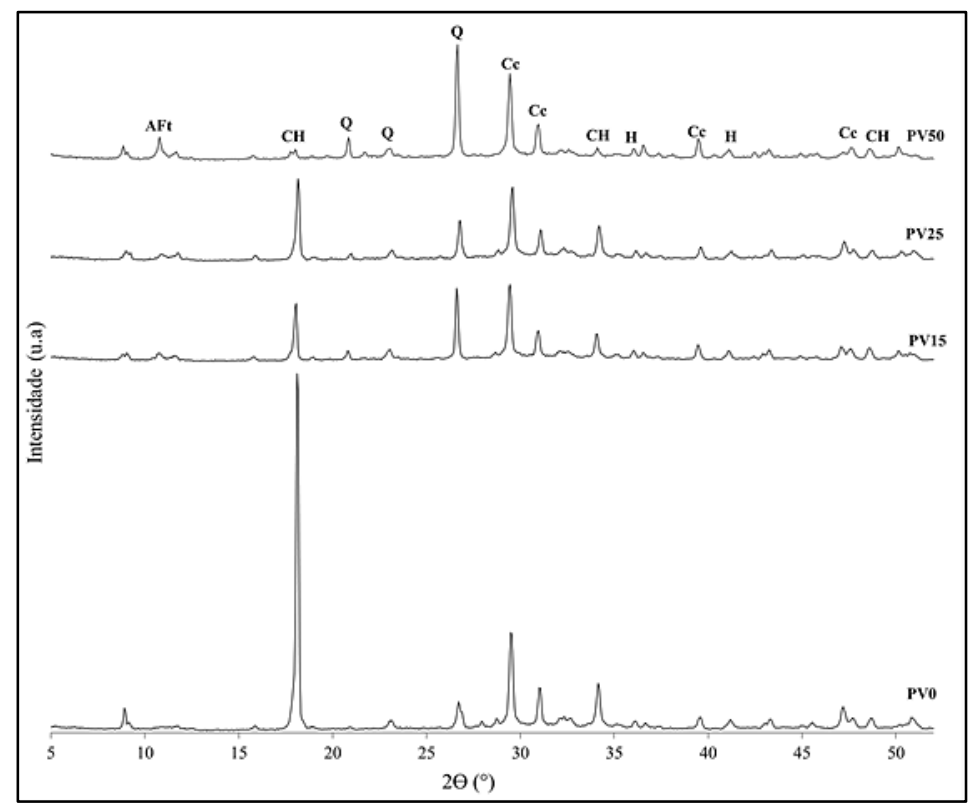

Figura 2: Difratograma das amostras (placas) PV0, PV15, PV25 e PV50. AFt - Etringita, H - Hematita, Q - Quartzo, Cc - Carbonato de cálcio, CH - Hidróxido de Cálcio.

\subsection{Análises termogravimétricas}

A análise termogravimétrica (TG) é usada para quantificar certas fases hidratadas através da perda de massa causada pela desidratação, descarbonetação ou decomposição dos hidratados devido elevação da temperatura.

Os resultados dos ensaios de termogravimetria das amostras das placas de fibrocimento são apresentados na Figura 3, sob a forma de curvas TG e DTG das placas com 100\% do cimento Portland CP V- ARI e substituições parciais de $15 \%, 25 \%$ e $50 \%$ do cimento pelo resíduo cerâmico, aos 28 dias de hidratação. Foi possível identificar os compostos hidratados de forma a confirmar os picos observados nas análises de DRX, bem como a formação de C-S-H em todas as misturas.
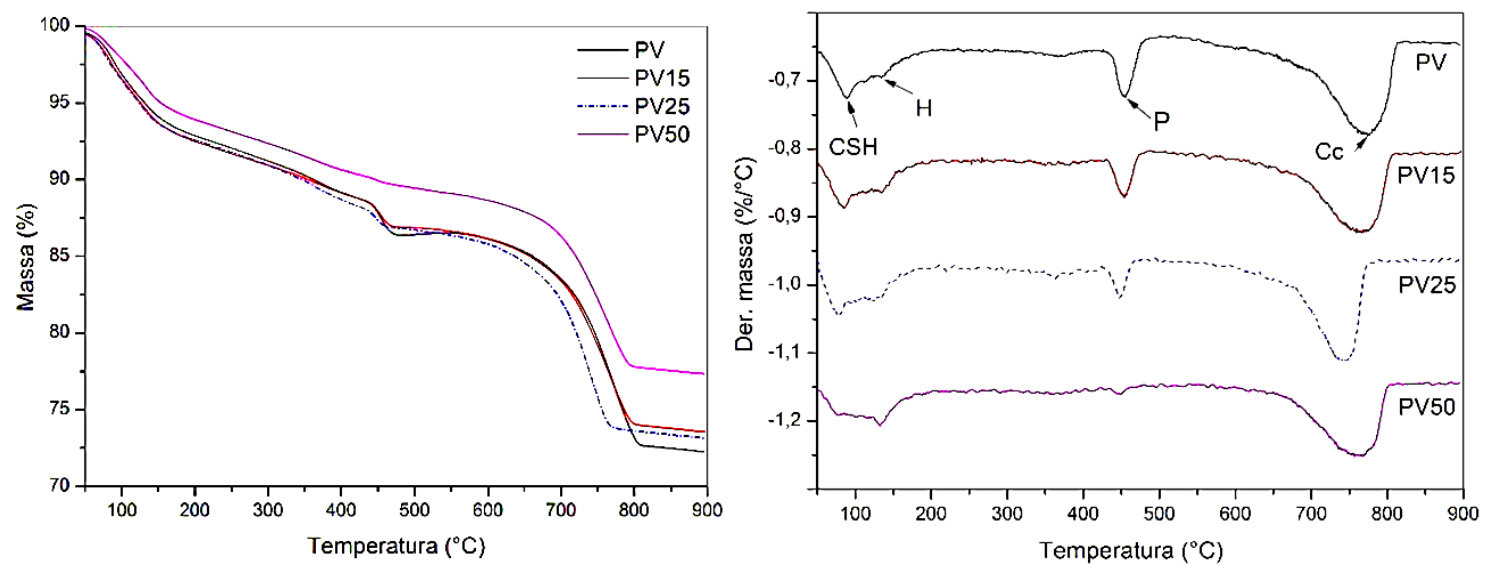

Figura 3: Análise termogravimetrica, curvas TG e DTG das amostras (placas) PV (0\%), PV15 (15\%), PV25 (25\%) e PV50 (50\%). C-S-H - Silicato de cálcio hidratado, H - Hematita, P - Portlandita, Cc- Carbonato de Cálcio $\left(\mathrm{CaCO}_{3}\right)$.

\subsection{Microscopia eletrônica de varredura (MEV)}

As análises de MEV, Figura 4 (a, b, c), foram realizadas com o objetivo de buscar imagens dos compostos hidratados observados nas demais análises de DRX, além de analisar a interação matriz/fibras. Na Figura 5 (a, b, c) é possível observar a superfície das amostras, afim de verificar alterações na porosidade do material, ou seja, se as amostras contendo o RCV apresentam aumento no número de poros na superfície quando comparadas à amostra referência. Dessa forma, pode-se verificar que nenhuma das imagens analisadas (Figura 5) apresentaram aumento significativo no número de poros na superfície, sendo analisado somente os macroporos, os quais influenciam mais fortemente na resistência mecânica dos materiais. 


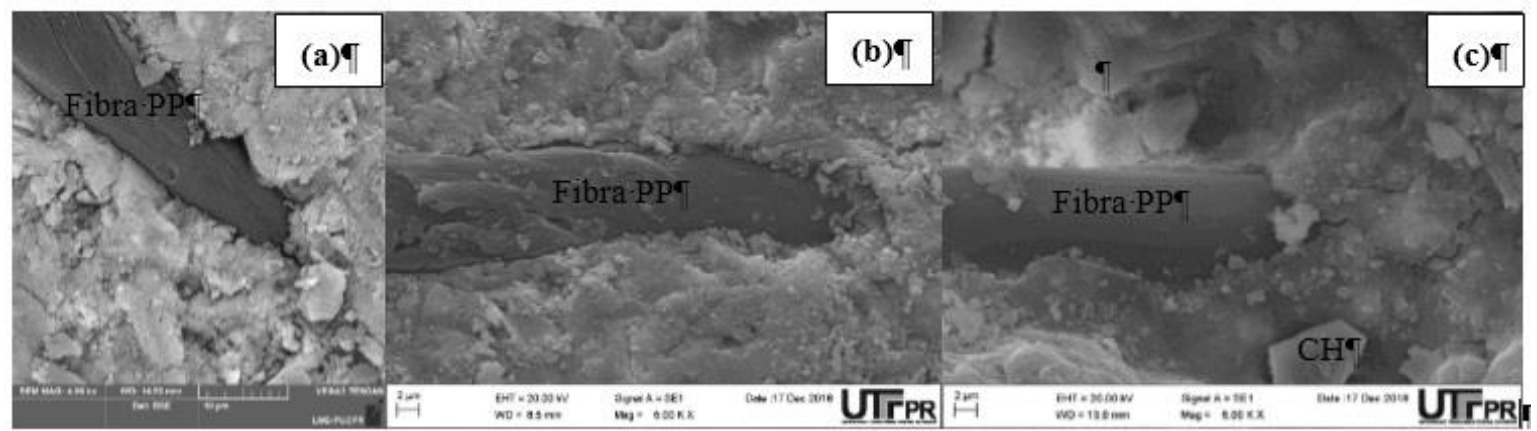

Figura 4: MEV das amostras (placas) PV (a), PV25(b), PV50 (c)

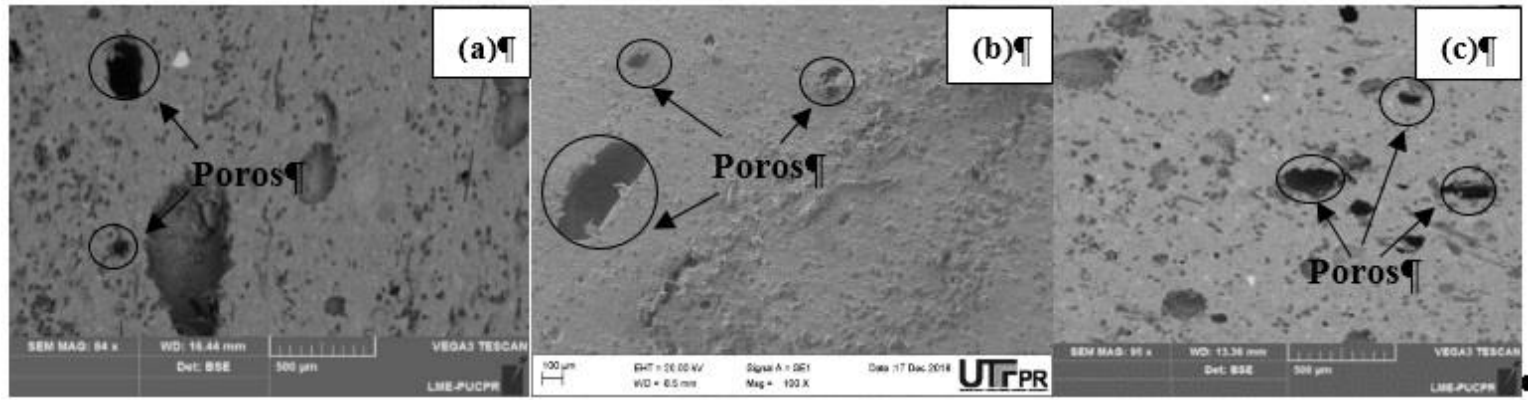

Figura 5: MEV das amostras (placas) PV (a), PV15 (b), PV25 (c)

\section{DISCUSSÃO}

A composição química do resíduo cerâmico moído indica que o mesmo possui um teor de $\mathrm{Al}_{2} \mathrm{O}_{3}+\mathrm{SiO}_{2}+\mathrm{Fe}_{2} \mathrm{O}_{3}$ de 93,55\% (Tabela 2), atendendo aos limites da NBR 12653 (2015) para o uso como material pozolânico em misturas com cimento Portland. Além disso para DOBIAS e POKORNY (2017) [9], um alto teor de $\mathrm{SiO}_{2}$ e um baixo teor de $\mathrm{CaO}$ no RCV podem contribuir para manter a resistência em materiais cimentícios. O cimento CP V ARI foi utilizado por conter um maior teor de clínquer dentre os cimentos disponíveis e, assim, consiste em um cimento "mais puro" em termos de adições minerais, além de apresentar uma moagem mais fina que o torna mais reativo.

As fibras utilizadas são responsáveis por grande parte da resistência à flexão das placas por apresentarem multifilamentos, o que proporciona um reforço multidirecional em uma matriz cimentícia e com uma densidade menor que os demais materiais, contribuindo assim, para redução da massa específica do produto final.

A análise ANOVA com nível de confiança de 95\% foi realizada para comparar estatisticamente a influência da substituição parcial do cimento Portland pelo RCV moído nas placas de fibrocimento em relação ao ensaio de resistência mecânica a flexão, considerando somente os dados obtidos aos 28 dias de hidratação. O resultado foi um "p-valor" de 0,211 (Tabela 3), superior ao "alfa" $(0,05)$, rejeitando-se a hipótese de diferença entre suas médias, confirmando que o RCV não exerce influência significativa na resistência à flexão, o que corrobora com estudos já realizados por ARAUJO (2017) [2] e GONLÇALVES et al. (2009) [3], onde esses autores também observaram resultados promissores ao analisarem a resistência mecânica em suas amostras.

A equivalência nas resistências à flexão entre as placas com substituição e a referência podem ser justificadas pela alteração da quantidade de silicato de cálcio hidratado (C-S-H) proporcionada pela reação pozolânica, juntamente ao desenvolvimento de uma estrutura interna menos porosa, devido as mudanças no tamanho médio dos poros, na distribuição do tamanho dos poros, sendo o RCV um material com uma superfície específica superior ao cimento Portland. A superfície das amostras pode ser observada nas imagens de MEV (Figura 4), onde não apresentam visualmente aumento de poros, quando comparado as imagens da amostra referência e a PV15

A quantidade de $\mathrm{CH}$ presente em uma matriz de cimento com adição de material fino ou pozolânico depende dos níveis dessa substituição, onde o pico de $\mathrm{CH}$ pode diminuir devido ao consumo durante uma reação química pozolânica, contribuindo para resultados satisfatórios encontrados na resistência mecânica [17 19], o que também foi confirmado nos resultados de DRX , onde as amostras produzidas com substituição do cimento por RCV tiveram redução nos picos de $\mathrm{CH}$. 
Para ambas as misturas, foram identificados o posicionamento das curvas nos intervalos correspondentes ao pico de C-S-H (entre 50 e $220^{\circ} \mathrm{C}$ - Figura 3), que é devido à remoção de água evaporável e decomposição das partes amorfas de C-S-H e sulfoaluminatos de cálcio. É possível perceber um pico característico da desidratação da Portlandita (P) (entre $400-500{ }^{\circ} \mathrm{C}$ - Figura 3), este aumento está correlacionado com o aumento da quantidade hidróxido de cálcio (Portlandita) formada como resultado da hidratação do cimento [17, 20].

$\mathrm{Na}$ faixa de temperatura de 600 a $850{ }^{\circ} \mathrm{C}$ (Figura 3) está localizado o pico característico da decomposição de carbonato de cálcio, indicando a carbonatação de algumas partes dos hidratos formados durante o manuseio dos espécimes e pela presença do fíler calcário adicionado a mistura. A perda de massa deste pico é responsável pelos diferentes graus de carbonatação das amostras, neste caso não houve alterações na intensidade desses picos.

Nas imagens de MEV, Figura 4 (a, b e c) pode-se perceber a aderência entre a interface matriz/fibra em todas as misturas, tanto na referência quanto nas demais amostras com $25 \%$ e $50 \%$ de RCV. Do mesmo modo, observando a superfície da amostra referência Figura 5 (a) em relação as demais amostras com 15 e 25\% nas imagens de MEV Figura 5 (b e c), não é possível afirmar que houve alteração significativa no número de poros ou em relação a presença de espaços vazios. Confirmando dessa forma, os resultados já observados em estudos realizados por HANSEN et al. (2015) [21] e OLIVEIRA (2012) [22] onde a presença do RCV não afetou expressivamente as propriedades dos materiais analisados.

Ao associar os resultados das análises de resistência mecânica à flexão e a caracterização microestrutural das amostras, por meio dos ensaios de DRX, MEV, TG/DTG, todas as misturas apresentaram um comportamento similar, sendo que as amostras contendo RCV não apresentaram nenhuma característica que venham a comprometer a estrutura do material.

\section{CONCLUSÕES}

No presente estudo foi investigado o uso do RCV na fabricação de placas em fibrocimento, em substituição ao cimento CP V ARI. Pode-se verificar que o RCV apresentou comportamento pozolânico pelo teste de pozolanicidade de $94 \%$ comprovados pelos resultados de resistência à flexão (MOR) onde, mesmo com a substituição de 15, 25 e 50\% não mostrou redução significativa de resistência, mantendo-se na ordem de 9,53, 8,79 e 7,71 Mpa. Sendo que, as microestruturas e as interações entre as diferentes fases sólidas podem ser responsáveis pelas variações nas propriedades mecânicas.

A principal influência do RCV na microestrutura do compósito foi a interação do material com $\mathrm{CH}$, devido ao consumo deste composto em consequência da reação pozolânica, comprovado pelas análises de DRX, e a formação de C-S-H apontado pelos resultados de TG e DTG, garantindo assim a resistência à flexão das placas.

Mesmo com a substituição em volume de até $50 \%$ de cimento por RCV, os resultados são muito promissores onde, a resistência à flexão pode alcançar 6,43 e 7,71 Mpa aos 7 e 28 dias, respectivamente, atendendo a classificação da NBR 15498 para uso externo, Classe A, categoria 3.

Assim, pode-se dizer que as placas de fibrocimento, com substituição parcial do cimento por resíduos de cerâmica vermelha, poderiam perfeitamente gerar produtos de larga aplicação na construção civil, contribuindo com o meio ambiente e redução de custos por se utilizar uma quantidade menor de cimento, isso, quando comparados aos produtos comumente empregados. Porém, para os casos de aplicação externa na envoltória das edificações, estudos a respeito da durabilidade devem ser conduzidos.

\section{BIBLIOGRAFIA}

[1] GARCIA, E., JUNIOR, M.C., QUARCIONI,V.Â., et al. "Resíduo de cerâmica vermelha ( RCV ): Uma alternativa como material pozolânico", Cerâmica Industrial, Janeiro 2014, pp. 31-38, 2014.

[2] ARAÚJO, R.A., "Influência da utilização de resíduo de cerâmica vermelha nas propriedades de argamassas mistas", Dissertação de mestrado, PPGEC/UFRGN, Natal, RN, 2017.

[3] GONÇALVES, J.P., TAVARES, L.M., TOLEDO FILHO, R.D., et al. "Performance evaluation of cement mortars modified with metakaolin or ground brick", Constr. Build. Mater., v. 23, n' 5, pp. 1971-1979, 2009.

[4] LAVAT, A.E., TREZZA, M.A., POGGI, E.M. "Characterization of ceramic roof tile wastes as pozzolanic admixture", Waste Manag., v. 29, n. 5, pp. 1666-1674, 2009.

[5] RAVAL, A.D., PATEL, I.N., PITRODA, E.J."Stone waste: Effective replacement of cement for 
establishing green concrete", Int. J. Innov. Technol. Explor. Eng., v. 2, n. 5, pp. 24-27, 2013.

[6] DOS ANJOS, M.A.S., GHAVAMI, K., BARBOSA, E.N.P. "Compósitos à base de cimento reforçados com polpa celulósica de bambu. Parte I: Determinação do teor de reforço ótimo", Rev. Bras. Eng. Agrícola e Ambient. - Agriambi, v. 7, n. 2, pp. 339-345, 2003.

[7] DOS ANJOS, M.A.S. "Compósito à base de cimento reforçado com polpa de bambu - Caracterização física, mecânica e microestrutural", Dissertação de mestrado, PUC Rio de Janeiro. Rio de Janeiro. 2002.

[8] PICANÇO, M.S., ANGELICA, R.S., BARATA, M.S., "Cimentos portland aditivados com arenito zeolítico com propriedades pozolânicas," Rev. Mater., v. 19, n. 2, pp. 68-80, 2014.

[9] DOBIAS, D., POKORNY, P. "Influence of Partial Replacement of Hydraulic Binder by Ground Brick on the Characteristics of Composites", Procedia Eng., v. 190, pp. 568-574, 2017.

[10] ABNT, NBR 16372 - Cimento Portland e outros materiais em Pó - Determinação da finura pelo método de permeabilidade ao ar (Método de Blaine). Rio de Janeiro, 2015.

[11] ABNT, NBR 16605 -Cimento Portland e outros materiais em pó - Determinação da massa específica. Rio de Janeiro, 2017.

[12] ABNT, "NBR 5752 - Índice de atividade pozolânica.” 2014.

[13] BETIOLI, A.M., JOHN, V.M., PILEGGI, E.R.G. "Equipamento para produção de placas de fibrocimento em laboratório", $I^{\circ}$ Seminário de Pesquisa, Extensão e Inovação do IF-SC, v. 1, Criciúma, pp. 64-66, 2011.

[14] CALDAS E SILVA, A. "Estudo da durabilidade de compósitos reforçados com fibras de celulose", 2002. 145 f. Dissertação de mestrado, Escola Politécnica/PUC São Paulo, São Paulo, 2002.

[15] URREA-CEFERINO, G.E., REMPE, N., DOS SANTOS, V., et al. "Definition of optimal parameters for supercritical carbonation treatment of vegetable fiber-cement composites at a very early age", Constr. Build. Mater., v. 152, pp. 424-433, 2017.

[16] CALDAS E SILVA, A., SAVASTANO JR, H., JOHN, E.V.M. "Envelhecimento de compósitos à base de escória de alto-forno reforçados com polpa celulósica residual de eucalipto", Ambient. Construído, v. 9, n. 1, p. 25-44, 2009.

[17] ABDELLI, K., TAHLAITI, M., BELARBI, R., et al. "Influence of the pozzolanic reactivity of the Blast Furnace Slag (BFS) and metakaolin on mortars", Energy Procedia, v. 139, pp. 224-229, 2017.

[18] TIRONI, A., CASTEllanO, C.C., BONAVETTI, V., et al. "Blended Cements Elaborated with Kaolinitic Calcined Clays", Procedia Mater. Sci., v. 8, pp. 211-217, 2015.

[19] HASSE, J.A. ANGULSKI DA LUZ, C., PEREIRA FILHO, J.I., et al. "Influência do Uso de Adição de Fíler Cerâmico de Resíduos de Construção e Demolição em Concretos Auto Adensável", In: 59 Congresso Brasileiro do Concreto (Ibracon), vol. 59, p. São Paulo: IBRACON, 2017.

[20] EL-GAMAL, S.M.A., EL-HOSINY, F.I., AMIN, M.S., et al."Ceramic waste as an efficient material for enhancing the fire resistance and mechanical properties of hardened Portland cement pastes", Constr. Build. Mater., v. 154, p. 1062-1078, 2017.

[21] HANSEN, D.M., BREHM, F.A., MORAES, C.A.M., et al. Aplicação De Resíduo Cerâmico Calcinado Como Pozolana : Application of Calcined Ceramic Waste As Pozzolan : a Review. $6^{\circ}$ Forum internacional de resíduos sólidos. Anais...São José dos Campus, SP: 2015

[22] OLIVEIRA, A.D.N. Estudo da substituição parcial do cimento Portland por resíduos de cerâmcia vermelha. Monografia: Departamento de Ciências Ambientais e Tecnológicas. Universidade Federal Rural do Semi - Árido - UFERSA. Mossoró - RN, 2012.

\section{ORCID}

Claudia Regina Bernardi Baldin

José Ilo Pereira Filho

https://orcid.org/0000-0003-0852-9526

Vitor Baldin

https://orcid.org/0000-0003-1055-6451

https://orcid.org/0000-0001-8672-842X 